\title{
Advanced Applications of Biomaterials Based on Alginic Acid
}

\author{
Lagopati $\mathrm{N}$ and Pavlatou EA* \\ Laboratory of General Chemistry, School of Chemical Engineering, National Technical University of Athens, Zografou Campus, Athens, Greece
}

*Corresponding author: Pavlatou EA, Laboratory of General Chemistry, School of Chemical Engineering, National Technical University of Athens, Zografou Campus, Athens, Greece

To Cite This Article: Lagopati N, Pavlatou EA. Advanced Applications of Biomaterials Based on Alginic Acid. 2020 - 9(1). AJBSR.MS.ID.001350. DOI: 10.34297 /AJBSR.2020.09.001350.

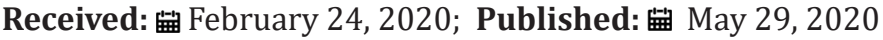

\begin{abstract}
Alginic acid, also known as algin or alginate, is a natural carbohydrate, which is derived from marine brown algae, as well as some microorganisms. It can be used in various applications. In particular, alginate has shown great potential in the areas of wound healing, drug delivery, in vitro cell culture, and tissue engineering, allowing the categorization of it as a promising biomaterial, or a basic component of other biomaterials. The unique characteristics of alginic acid, such as the biocompatibility, the mild required gelation conditions, the low toxicity, the relative low cost and the simple modifications, allow the development of alginate hydrogels, and alginate derivatives with enhanced properties. The aim of this review, is to present an overview of the properties of alginate, shedding light on the current and potential applications and suggesting new perspectives for future studies.
\end{abstract}

\section{Introduction}

Innovative biomaterials made of various constituents seems to be very attractive for biomedical and pharmaceutical applications [1]. Recently, the increasing needs for raw materials, in order to be used for the development of various biomaterials and applications, lead to the use of materials, derived from the nature [2]. Nature materials were utilized in biomedical application, such as in wound healing or in prosthetics, but eventually there were replaced by synthetic polymers and ceramics in the previous century [2]. The new trend in the design of biomaterials focuses on biomimetic approach [3]. Thus, natural materials have currently regained the attention of material science and engineering [4]. Since, a significant part of the earth's surface is covered by water, it is reasonable that marine flora and fauna are characterized by a great biodiversity [5]. Thus, marine life provides a variety of choices, depending on the desirable properties [6]. It has been reported that many aquatic organisms possess antibacterial, anti-fungal, anti-inflammatory, anticancer neuroprotective, analgesic and immunomodulator properties [6].

In the surface of brown seaweeds, it is usual to find novel bacteria containing alginate lyase(s), which is the target microorganism, for extracting alginate [7]. Thus, marine algae are considered as a significant source of natural polysaccharides and various nutriments, such as vitamins, sterols, salts, with original physical properties $[8,9]$.

Alginic acid, also known as algin or alginate, is a natural anionic carbohydrate. Actually, alginate is a linear polysaccharide [10]. It is derived from marine brown algae, as well as some microorganisms [11] (Figure 1). The properties of alginate, including biocompatibility, low toxicity, relative low cost and ease of gelation, make it an ideal biomaterial for various applications, related to the food, chemical, medical, and agricultural industries [12]. Particularly, the structural similarity of alginic acid to extracellular matrices of living tissues, allow wide applications in wound healing, drug delivery systems, tissue engineering and cell transplantation $[13,10]$.

This is an extensive review of the general properties of alginic acid and the related suggesting new perspectives for future studies. current and potential applications in biomedical science and engineering. 


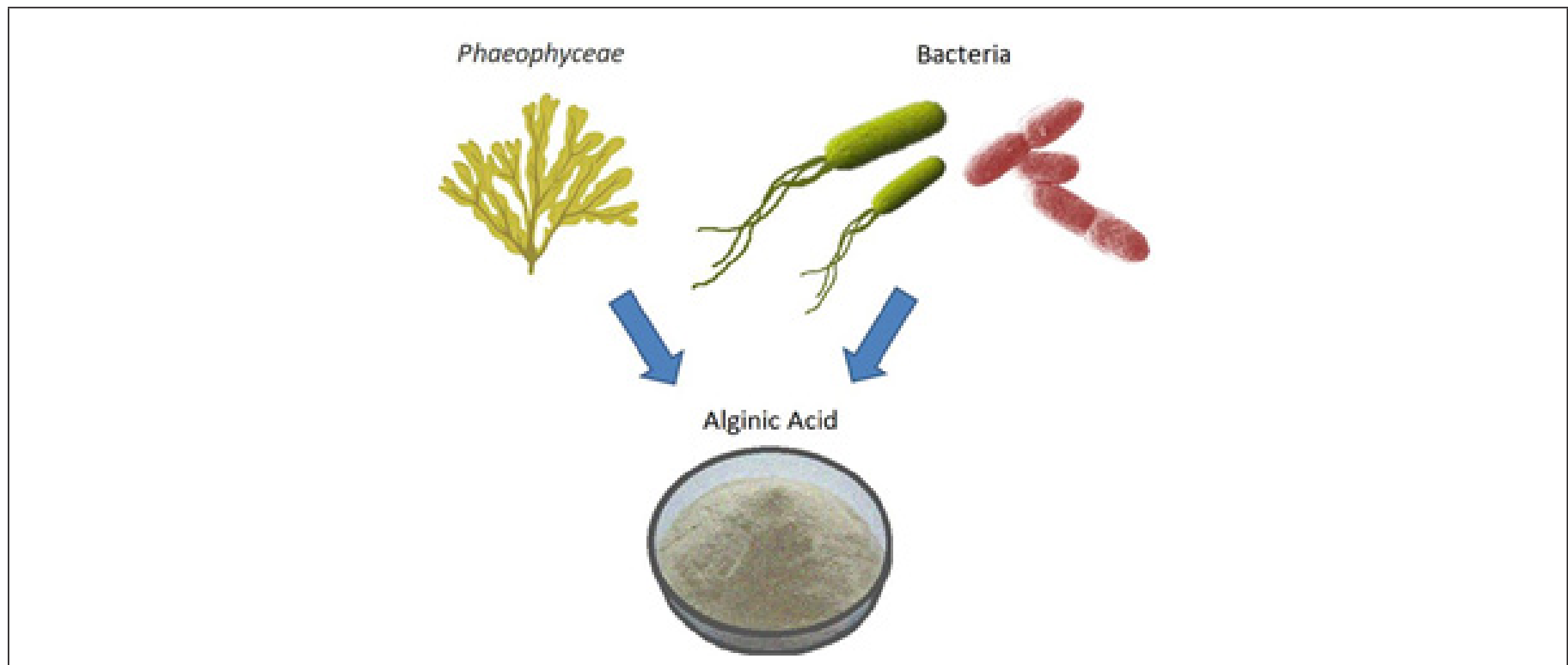

Figure 1: Alginic Acid is derived from marine brown algae, known as Phaeophyceae, as well as some micro-organisms, such as bacterial genera Pseudomonas and Azotobacter.

\section{Alginic Acid structure and properties}

\section{Origins and extraction of Alginic Acid}

Alginic acid is one of the most popular and intensely studied natural biopolymers [1]. The alginate is typically originated from brown algae, known as Phaeophyceae, including Laminaria hyperborea, Laminaria digitata, Laminaria japonica, Ascophyllum nodosum, and Macrocystis pyrifera [10]. The extraction employs aqueous alkali solutions, such as $\mathrm{NaOH}$ [13], the extract is filtered and sodium or alternatively calcium chloride is utilized to precipitate the alginic salt, which can be transformed to alginic acid by dilution of $\mathrm{HCl}$ [14]. The final alginate acid is produced by further purification and conversion [10].

Alginic acid is also derived from bacterial genera Pseudomonas and Azotobacter. In fact, this kind of biosynthesis provides alginate with more defined physical properties compared to that obtained from algae-derived alginate [15].

Four common biogenic synthesis of alginic acid have been reported: a) Precursor substrate synthesis,

b) Polymerization and cytoplasmic membrane transfer,

c) Periplasmic transfer and modification and

d) Export through the outer membrane [16].

\section{Structure and properties of Alginate}

Depending on the algae species, the age, the type and the condition of the tissues, as well as the process of extraction, the quantity and quality of the alginates varies [17]. Alginates are actually linear copolymers with blocks of $(1 \rightarrow 4)$ - $\alpha$-L-guluronic acid $(\mathrm{G}),(1 \rightarrow 4)$ - $\beta$-D-mannuronic acid blocks $(\mathrm{M})$ and heteropolymeric sequences of $M$ and $G$ (MG blocks) [18](Figure 2). The M/G ratio as well as the length of each block can be estimated through proton NMR depends on the natural source [19]. The different combinations between $\mathrm{M}$ and $\mathrm{G}$ blocks, lead to the manufacture of at least 200 different alginates [10]. Purified alginates have the potential to form fibers, beads, hydrogels, or films particularly in presence of calcium. However, it must be mentioned that MM and MG blocks can interact with calcium counterions.

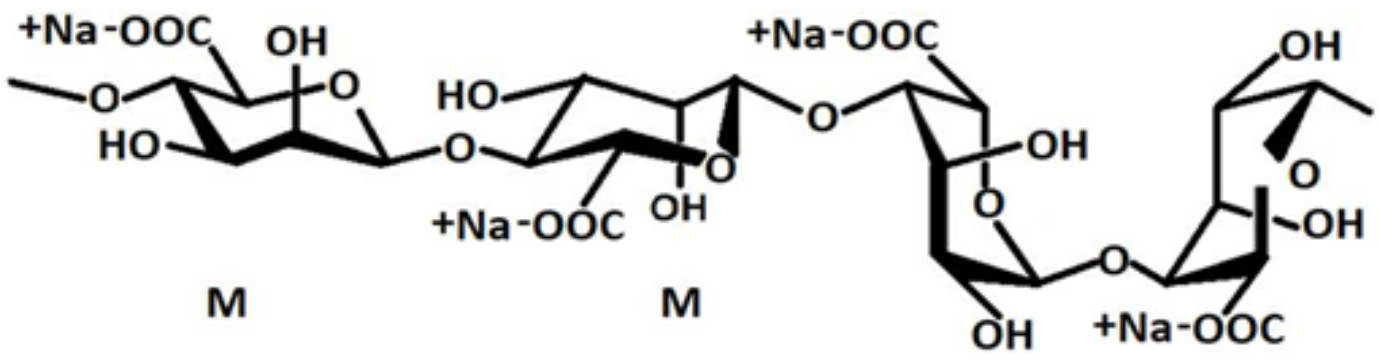

G

G

Figure 2: Chemical structures of guluronic $(\mathrm{G})$ and mannuronic $(\mathrm{M})$ acid blocks involved in alginic acid. 


\section{Alginate hydrogels}

Alginate can be used in a hydrogel form in biomedicine, for wound healing, drug delivery and tissue engineering applications [20]. Hydrogels are 3-D cross-linked networks synthesized mainly by hydrophilic polymers [21]. They are typically biocompatible, due to the similarity of their structure with various biomolecules [12].

Alginate hydrogels can be prepared by various cross-linking methods, such as chemical or physical cross-linking of hydrophilic polymers, via gelation process [22]. George $\mathrm{M}$ et al. support the idea that only the G-blocks participate in intermolecular cross-linking with divalent cations, forming hydrogels [23]. The existence of GG block content in an alginate hydrogel has a direct impact on the stiffness of the final product [24]. Particularly the sodium alginate, as a typical example of the monovalent salt form of alginate, presents a high water-solubility, increasing the solvent viscosity upon dissolution and allowing the use in interesting applications [25]. The average molar mass, and the distribution of the molar masses also controls the viscosity of the solution as well as the stiffness of the hydrogels [10]. Actually, increasing the molecular weight of an alginate, the physical properties of the resultant hydrogel are improved [10]. In alginic medium, alginate may provide gels based in H-bond network [18]. The ion-exchange properties of alginic acid are very important, since they allow strong interactions with $\mathrm{Ba}, \mathrm{Sr}$ and $\mathrm{Ca}$, resulting to a hydrogel with reversibility in the presence of large excess of monovalent salts or other complex compounds [8].

It is important to be mentioned that the physical properties control the stability of the gels and the rate of drug release from the alginate hydrogels [10]. Alginic acid is non-degradable in mammals, since they lack the enzyme "alginase", which is responsible for the cleavage of the polymer chains [26]. The ionically cross-linked alginate gels can be dissolved, under specific conditions, such as when creating partial oxidation of alginate chains [27]. However, even in this case, the alginates cannot be completely removed from the body, because the average molecular weight is higher than the renal clearance threshold of the kidneys [10].

\section{Derivatives of Alginic acid}

Amphiphilic alginate: Various alginate derivatives are utilized in a wide range of biomedical applications. Perhaps the most common type of alginate derivates is the amphiphilic alginate which is synthesized by introducing hydrophobic moieties [11]. Among the main advantages of the amphiphilic alginates is that they can form self-assembled structures in aqueous media, and that they have the potential to be used in various drug delivery systems [28].

Amphiphilic derivatives of sodium alginate can be produced through the conjugation of long alkyl chains, via ester bond formation [29]. Aqueous solutions of these alginate derivatives could be exploited in cartilage repair and regeneration approaches
[20]. Additionally, microparticles can be prepared from these amphiphilic derivatives by dispersion in a sodium chloride solution, allowing the encapsulation of proteins and their release, in the presence of surfactants that disrupt intermolecular hydrophobic junctions or esterases which hydrolyze the ester bonds between alkyl chains and the alginate backbone [10]. Furthermore, hydrogels can be prepared from this alginate derivatives, providing long-term stability in aqueous media [30].

Cell-interactive alginate: Recently another category of alginate derivatives, containing cell-adhesive peptides, has been gained attraction [31]. These compounds can be prepared through the addition of peptides, such as side-chains [32]. Appropriate ligands are of crucial importance to regulate cellular interactions, particularly for tissue engineering applications, since alginate lacks mammalian cell-adhesivity [33]. Peptides including the triplet (RGD) are widely used as model adhesion ligands, due to the wide-spread existence of integrin receptors for this ligand on various cell types [34]. These peptides can be chemically coupled to the alginate backbone [10]. A minimum concentration of RGD peptides in alginate gels is needed for the adhesion and growth of cells, and this ratio is perhaps cell type - dependent [35]. The affinity of the RGD peptide is another important parameter. Cyclic RGD peptides are considered to be more potent and are needed at lower concentrations than linear RGD peptides [34]. Also, various peptides, containing either the DGEA (Asp-Gly-Glu-Ala) or the YIGSR (Tyr-Ile-Gly-Ser-Arg) sequences have also been utilized for the modification of alginate gels [10].

\section{Applications of alginic acid}

\section{Application of alginic acid in industry}

Alginates in Food Industry: The most common applications of alginates are based on their gel-forming ability. Their properties make them quite suitable in the field of food and beverages [36]. They are completely organic and for this reason they are considered as safe substances for food applications [36]. Thus, alginates are widely used as food additives in jams and jellies, to improve and stabilize the structure of food [37]. They are capable of thickening a solution, whenever they are dissolved in water and they have the ability to form either gels whenever they are added to a calcium salt solution or sodium or calcium alginate films and calcium alginate fibers [10]. For the aforementioned reasons, alginates are used as enhancers of viscosity, stability and for emulsifying solutions, to enhance food preservation, improve flavor, taste, and appearance of the food [36]. For safety reasons, in Europe, regulations assign each additive a unique number, the well-known "E numbers," for each and every approved additive [38]. The regulatory status of alginic acid products, which are widely known as E 401, E 402, E 403, E 404, and E 405, in dietary supplements, is summarized in Table 1. 
Table 1: Regulatory status for alginate products.

\begin{tabular}{|c|c|c|}
\hline \multirow{2}{*}{ Product } & \multicolumn{2}{|c|}{ Regulatory Status } \\
\cline { 2 - 3 } & European Union & United States of America \\
\hline Sodium alginate & E 401 & GRAS, 21 CFR 184.1724 21 CFR 184.1610 \\
\hline Potassiun alginate & E 402 & GRAS, 21 CFR 184.1133 \\
\hline Ammonium alginate & E 403 & GRAS, 21 CFR 184.1187 \\
\hline Calcium alginate & E 404 & 21 CFR 172.858 \\
\hline Propylene glycol alginate & E 405 & \\
\hline
\end{tabular}

\section{Alginates in packaging}

Nowadays, it is well established that packaging is very crucial for the containment and preservation of food products [39]. The materials that are widely used, are typically based on polymers from non-renewable sources, associated with environmental concerns [40]. Hence, several studies carried out in recent years have focused on the development of food packaging, based on natural polymers [41]. Alginate is perhaps the most widely studied essential biopolymer and it is considered as the preferred filmforming material [36].

\begin{tabular}{|c|c|c|}
\hline Alginate form & Additional compounds & Advantage \\
\hline \multirow{7}{*}{ Sodium alginate } & Silver nanoparticles & $\begin{array}{l}\text { Increase in shelf life of some fruits and vegetables (carrots, pears, } \\
\text { etc.) }\end{array}$ \\
\hline & Polyethyleneimine, poly(lactic acid) & Increase in oxygen barrier properties \\
\hline & $\begin{array}{l}\text { a. Montmorillonite/cellulose nanoparticles and } \\
\text { b. Montmorillonite clay }\end{array}$ & $\begin{array}{l}\text { a. Reduction in the water vapor permeability, b. Reduction in the } \\
\text { water permeability and increase in the water solubility. }\end{array}$ \\
\hline & $\mathrm{CaCl}_{2}$ & $\begin{array}{l}\text { Improved mechanical properties, water resistance, Decrease } \\
\text { water vapor permeability }\end{array}$ \\
\hline & Lemongrass oil and glycerol & $\begin{array}{l}\text { Flexibility, Increased antimicrobial properties, mechanical } \\
\text { strength }\end{array}$ \\
\hline & Natamycin & $\begin{array}{c}\text { Increase water solubility, water vapor permeability and opacity; } \\
\text { Decreased tensile strength }\end{array}$ \\
\hline & Lysozyme, nisin, ethylenediaminetetraacetic acid & Antimicrobial effect \\
\hline Food-grade alginate & - & Preserves quality of mushrooms and increases the shelf life \\
\hline \multirow{3}{*}{ Alginate cast film } & Glycerol and sorbitol & Positive influence on the mechanical properties. \\
\hline & Enterocins and high-pressure processing & Delayed growth of L. monocytogenes \\
\hline & Potassium sorbate & Potential use for release of active substances \\
\hline \multirow{3}{*}{ Calcium alginate } & Silver-montmorillonite nanoparticles & Prevents dehydration, Antimicrobial effect, Increased shelf life \\
\hline & Nisin & Suppression of bacterial growth \\
\hline & - & Lowered shrinkage loss \\
\hline $\begin{array}{l}\text { Biocomposite film of cellulose } \\
\text { and alginate }\end{array}$ & $\begin{array}{l}\text { Microfibrillated cellulose, nanofibrillated } \\
\text { cellulose, nanofibrillated anionic dicarboxylic } \\
\text { acid cellulose }\end{array}$ & $\begin{array}{l}\text { Increased mechanical properties, increased grease barrier } \\
\text { properties, decreased water vapor permeability }\end{array}$ \\
\hline $\begin{array}{l}\text { Gelatine/sodium alginate } \\
\text { blend }\end{array}$ & Corn oil, olive oil & Minimizes water loss \\
\hline Propylene glycol alginate & Soy protein isolate films & $\begin{array}{c}\text { Tensile strength increased, decreased water vapor permeability } \\
\text { and solubility }\end{array}$ \\
\hline
\end{tabular}

Active packaging is currently the key technology, preserving food quality via the controlled release of active agents from the packaging [42]. For instance, in order to avoid lack of crunchiness, during cooking or warming breaded foods in a microwave oven, new products based in the active packaging, are proposed, usually including alginate gel film of alginate gel [8]. Thus, antimicrobial packaging with lactic acid bacteria, embedded in alginate film matrix allows to control the growth of food-borne pathogens [43]. Also, antiradical properties are obtained in the presence of oregano-based film made of polycaprolactone/alginate-calcium film [44]. Table 2 summarizes the applications of alginate in food packaging, gathering the advantages of them [45].

\section{Alginates in paper and textiles}

Alginic acid enriched with calcium and mixed with starch presents high water retention in paper coating (Rinaudo M., 2014). This property is very important for size press coating formulation, improving coating rheology, controlling migration 
and increasing coat weight uniformity [46]. Alginate fibers are widely used as wound management materials [47]. The common process to produce highly absorbent wound dressing materials is wet-spinning [1]. The mixture of alginate with sodium and calcium fibers result to a final product with high wet integrity, due to calcium and enhanced absorbency, due to sodium [10]. Alginate fibers and silver fibers can improve the anti-microbial properties, while zinc fibers can act as immune modulators [48]. Alginate calcium fibers, prepared via wet-spinning process, possess high tensile strength, desirable property for cloth materials [49]. The combination of yarns and textile of alginate calcium fibers lead to a nice feeling and strength [8].

\section{Biomedical applications of alginic acid}

Alginate hydrogels are quite attractive in wound healing, drug delivery, and tissue engineering applications [10]. This fact is related to the structural similarity of the hydrogels to the extracellular matrices in tissues and for this reason they can be manipulated, playing several critical roles [12]. In pharmaceutical industry, purified alginates are utilized as stabilizer in solution and dispersion of solid substances [8]. The main uses of alginates in biomedical applications are associated with controlled drug release, cells encapsulation, scaffolds in ligament, tendon tissue engineering and preparation of moulds in dentistry [20].

Alginic acid is also used in certain medications, such as Gaviscon liquid, creating a foam barrier for coating the stomach [50]. It is often combined with aluminum hydroxide and magnesium carbonate to form antacids. This combination of alginic acid, aluminum hydroxide, and magnesium carbonate can help to treat symptoms of stomach ulcers, gastroesophageal reflux disease and other conditions caused by excess stomach acid [51]. This medicine can be used for the treatment of heartburn, upset stomach, sour stomach, or acid indigestion. Alginate seems not to be absorbed or metabolized after ingestion [52].

New technology of medical textiles is an important field, showing great expansion, in the design and development of wound management products [53]. Fibers and dressings, which are fabricated to be used as wound care products ought to have hemostatic, anti-bacterial, anti-viral, fungistatic, non-toxic, high absorbent, non-allergic, breathable, biocompatible, and good mechanical properties [54]. Various materials are used for textile structures in modern wound dressings, such as sliver, yarn, crochet, braided, woven, non-woven, knitted and composite materials [55]. The addition of specialized additives can enhance the properties of advanced wound dressings [56]. Alginates can be used in hemostatic material and wound dressing [47]. Alginate wound dressings can maintain the normal moist microenvironment, minimizing bacterial infection at the wound, and facilitating wound healing [57].
Nanofibers are also used in wound care, since they gather unique properties, such as high surface area to volume ratio, nanoscale fiber diameter, porosity and light weight [58]. Alginate nanofibers, produced by electrospinning technique in presence of various synthetic polymers, can improve the processability [59].

Alginate wound dressings can absorb a large quantity of liquid inside the fiber structure, due to their unique gel blocking properties [60]. Furthermore, these wound dressings possess novel hemostatic and antimicrobial potential, promoting wound healing [47]. Thus, they are now widely used in the management of highly exuding wounds such as surgical wounds, leg ulcers and pressure sores [61]. Calcium alginate in wound dressing can provide hemostasis and tissue repair, since in contact with blood, $\mathrm{Ca}^{+2}$ ions can activate platelet aggregation, reducing the coagulation time [62]. Enhanced alginate with hydrolyzed chitosan shows improved antibacterial properties [63].

Alginate gelsallow the controlled release of drug molecules, from small chemical drugs to macromolecular proteins, depending on the cross-linker types and cross-linking methods [64]. Additionally, alginate hydrogels can be orally administrated or injected into the body allowing extensive pharmaceutical applications [65]. Furthermore, they are considered as promising candidates for cell transplantation in tissue engineering, by delivering cells to the target-area, providing space for new tissue formation, and controlling the structure and function of the engineered tissue [6668].

\section{Conclusion}

It is clear that alginates are natural polysaccharides which may be used in various applications. Biomedical and pharmaceutical applications of purified alginates seem certainly the most promising field of their applications. Particularly, alginate has shown great potential in the areas of wound healing, drug delivery, in vitro cell culture, and tissue engineering. Its biocompatibility, the mild required gelation conditions and the simple modifications, allow the development of alginate hydrogels, and alginate derivatives with enhanced properties. It is expected that in the future, the alginatebased materials which are designated to be used in medicine are likely to evolve considerably, particularly in active applications, like active packaging, active wound dressing and other smart systems. The production of new alginate polymer derivatives, with distinct properties, employing the use of genetic engineering, to control the biogenetic synthesis of alginate through bacteria, remains a great challenge.

\section{Acknowledgment}

«This research is implemented through IKY scholarships program and co-financed by the European Union (European Social Fund - ESF) and Greek national funds through the action entitled "Reinforcement of Postdoctoral Researchers", in the framework 
of the Operational Program "Human Resources Development Program, Education and Lifelong Learning" of the National Strategic Reference Framework (NSRF) 2014 - 2020 - MIS5001552».

\section{References}

1. Wróblewska Krepsztul J, Rydzkowski T, Michalska-Pożoga I, Thakur VK (2019) Biopolymers for Biomedical and Pharmaceutical Applications: Recent Advances and Overview of Alginate Electrospinning. Nanomaterials (Basel, Switzerland) 9(3): 404.

2. Song R, Murphy M, Li C, Ting K, Soo C, et al (2018) Current development of biodegradable polymeric materials for biomedical applications. Drug Des Devel Ther 12: 3117-3145.

3. Park KD, Wang X, Lee JY, Park KM, Zhang S, et al (2016) Research trends in biomimetic medical materials for tissue engineering: commentary. Biomaterials research. 20: 8 .

4. Perera AS, Coppens MO (2019) Re-designing materials for biomedical applications: from biomimicry to nature-inspired chemical engineering. Philosophical transactions. Series A, Mathematical, physical, and engineering sciences. 377 (2138): 20180268.

5. Dinerstein E, Vynne C, Sala E, Joshi AR, Fernando S, et al. (2019) A Global Deal For Nature: Guiding principles, milestones, and targets. Science advances. 5(4).

6. Malve H (2016) Exploring the ocean for new drug developments: Marine pharmacology. Journal of pharmacy \& bioallied sciences, 8(2): 83-91.

7. Inoue A (2018) Characterization of PL-7 Family Alginate Lyases From Marine Organisms and Their Applications. Chapter 16. In Methods in Enzymology. pp. 605.

8. Rinaudo M (2014) Biomaterials based on a natural polysaccharide: alginate. TIP Rev. Esp. Cienc Quím Biol 17 (1): 92-96.

9. Rinaudo M (2008) Main properties and current applications of some polysaccharides as biomaterials. Polymer International 57 (3), 397-430.

10. Lee KY, Mooney DJ (2012) Alginate: properties and biomedical applications. Progress in polymer science, 37(1): 106-126.

11. Szekalska M, Puciłowska A, Szymańska E, Ciosek P, Winnicka K (2016) Alginate: Current Use and Future Perspectives in Pharmaceutical and Biomedical Applications. International Journal of Polymer Science.

12. Catoira MC, Fusaro L, Francesco D, Ramella M, Boccafoschi F (2019) Overview of natural hydrogels for regenerative medicine applications. J Mater Sci Mater Med 30: 115.

13. Spadari CC, Lopes LB, Ishida K (2017) Potential Use of Alginate-Based Carriers As Antifungal Delivery System. Frontiers in microbiology 8: 97.

14. Pereira L, Cotas J (2020) Introductory Chapter: Alginates - A General Overview. In Alginates - Recent Uses of This Natural Polymer. Intech Open.

15. Hay ID, Ur Rehman Z, Moradali MF, Wang Y, Rehm BH (2013) Microbial alginate production, modification and its applications. Microbial biotechnology 6(6): 637-650.

16. Remminghorst U, Rehm BH (2006) Bacterial alginates: from biosynthesis to applications. Biotechnol Lett 28(21): 1701-1712.

17. Wells ML, Potin P, Craigie JS, Raven JA, Merchant SS, et al (2017) Algae as nutritional and functional food sources: revisiting our understanding. Journal of applied phycology 29(2): 949-982.

18. Andriamanantoanina H, Rinaudo M (2010) Relationship between the molecular structure of alginates and their gelation in acidic conditions. Polymer International (Special Issue: Dedicated to François Schué) 59 (11): 1531-1541.
19. Aarstad OA, Tondervik A, Sletta H, Skjak-Braek G (2012) Alginate sequencing: An analysis of block distribution in alginates using specific alginate degrading enzymes. Biomacromolecules 13: 106-116.

20.Sun J, Tan H (2013) Alginate-Based Biomaterials for Regenerative Medicine Applications. Materials (Basel Switzerland) 6(4): 1285-1309.

21. Chai Q, Jiao Y, Yu X (2017) Hydrogels for Biomedical Applications: Their Characteristics and the Mechanisms behind Them. Gels (Basel Switzerland) 3(1): 6 .

22. Dodero A, Pianella L, Vicini S, Alloisio M, Ottonelli M, et al (2019) Alginate-based hydrogels prepared via ionic gelation: An experimental design approach to predict the crosslinking degree. European Polymer Journal 118: 586-594

23. George M, Abraham TE (2006) Polyionic hydrocolloids for the intestinal delivery of protein drugs: Alginate and chitosan - a review. Journal of Controlled Release 114 (1): 1-14.

24. Aarstad O, Heggset EB, Pedersen IS, Bjørnøy SH, Syverud K, et al (2017) Mechanical Properties of Composite Hydrogels of Alginate and Cellulose Nanofibrils. Polymers (Basel, Switzerland), 9: 378.

25. Gurikov P, Smirnova I (2018) Non-Conventional Methods for Gelation of Alginate. Gels (Basel, Switzerland) 4(1): 14.

26. Gasperini L, Mano JF, Reis RL (2014) Natural polymers for the microencapsulation of cells. Journal of the Royal Society. Interface 11(100)

27. Freeman FE, Kelly DJ (2017) Tuning Alginate Bioink Stiffness and Composition for Controlled Growth Factor Delivery and to Spatially Direct MSC Fate within Bioprinted Tissues. Sci Rep 7: 17042.

28. Tesauro D, Accardo A, Diaferia C, Milano V, Guillon J, et al (2019) PeptideBased Drug-Delivery Systems in Biotechnological Applications: Recent Advances and Perspectives. Molecules (Basel, Switzerland) 24(2) 351.

29. Rodriguez S, Tuli R, Wheeler A, Nguyen A, Luong J, et al (2019) Current Perspective and Advancements of Alginate-Based Transplantation Technologies, Alginates - In "Recent Uses of This Natural Polymer", Leonel Pereira. Intech Open.

30. Araújo M, Bidarra SJ, Alves PM, Valcarcel J, Vázquez JA, et al (2020) Coumarin-grafted blue-emitting fluorescent alginate as a potentially valuable tool for biomedical applications. J Mater Chem B. 8: 813-825.

31. Mondal S, Das S, Nandi AK (2020) A review on recent advances in polymer and peptide hydrogels. Soft Matter 16: 1404-1454.

32. Joo SH (2012) Cyclic peptides as therapeutic agents and biochemical tools. Biomolecules \& therapeutics 20(1): 19-26.

33. Spicer CD (2020) Hydrogel scaffolds for tissue engineering: the importance of polymer choice. Polym Chem 11; 184-219.

34. Bellis SL (2011) Advantages of RGD peptides for directing cell association with biomaterials. Biomaterials 32(18): 4205-4210.

35. Caliari SR, Burdick JA (2016) A practical guide to hydrogels for cell culture. Nature methods 13(5): 405-414.

36. Senturk Parreidt T, Müller K, Schmid M (2018) Alginate-Based Edible Films and Coatings for Food Packaging Applications. Foods (Basel Switzerland) 7(10): 170 .

37. Saha D, Bhattacharya S (2010) Hydrocolloids as thickening and gelling agents in food: a critical review. J Food Sci Technol 47(6): 587-597.

38. Qin Y, Jiang J, Zhao L, Zhang J, Wang F (2018) Applications of Alginate as a Functional Food Ingredient. Chapter 13. In Biopolymers for Food Design. Elsevier Inc. pp. 409-429.

39. Müller P, Schmid M (2019) Intelligent Packaging in the Food Sector: A Brief Overview. Foods (Basel Switzerland) 8(1): 16. 
40. Song JH, Murphy RJ, Narayan R, Davies GB (2009) Biodegradable and compostable alternatives to conventional plastics. Philosophical transactions of the Royal Society of London. Series B, Biological sciences 364(1526): 2127-2139.

41. Muñoz Bonilla A, Echeverria C, Sonseca Á, Arrieta MP, Fernández García M (2019) Bio-Based Polymers with Antimicrobial Properties towards Sustainable Development. Materials (Basel Switzerland) 12(4): 641.

42. Biji KB, Ravishankar CN, Mohan CO, Srinivasa Gopal TK (2015) Smart packaging systems for food applications: a review. Journal of food science and technology 52(10): 6125-6135.

43. Huang T, Qian Y, Wei J, Zhou C (2019) Polymeric Antimicrobial Food Packaging and Its Applications. Polymers. 11(3): 560.

44. Salmieri S, Lacroix M (2006) Physicochemical Properties of Alginate/ Polycaprolactone Based Films Containing Essential Oils. J Agric Food Chem 54(26): 10205-10214.

45. Theagarajan R, Dutta S, Moses JA, Anandharamakrishnan C (2019) Alginates for Food Packaging Applications. Chapter 11. In: , Shakeel Ahmed (Ed.), Alginates pp. 207-232.

46. Müller K, Bugnicourt E, Latorre M, Jorda M, Echegoyen Sanz Y, et al (2017) Review on the Processing and Properties of Polymer Nanocomposites and Nanocoatings and Their Applications in the Packaging, Automotive and Solar Energy Fields. Nanomaterials (Basel Switzerland) 7(4): 74.

47. Aderibigbe BA, Buyana B (2018) Alginate in Wound Dressings. Pharmaceutics 10(2): 42 .

48. Yang K, Han Q, Chen B, Zheng Y, Zhang K, et al (2018) Antimicrobial hydrogels: promising materials for medical application. International journal of nanomedicine 13: 2217-2263.

49. Lin HY, Wang HW (2012) The influence of operating parameters on the drug release and antibacterial performances of alginate fibrous dressings prepared by wet spinning. Biomatter 2(4): 321-328.

50. Bor S, Kalkan IH, Çelebi A, Dinçer D, Akyüz F, et al (2019) Alginates: From the ocean to gastroesophageal reflux disease treatment. The Turkish journal of gastroenterology : the official journal of Turkish Society of Gastroenterology 30(Suppl 2): 109-136.

51. Yousaf M, Nirwan JS, Smith AM, Timmins PB, Conway R, et al (2019) Raftforming polysaccharides for the treatment of gastroesophageal reflux disease (GORD): Systematic review. Journal of applied polymer science 136 (40): 48012.

52. MacFarlane B (2018) Management of gastroesophageal reflux disease in adults: a pharmacist's perspective. Integrated pharmacy research \& practice $7: 41-52$.

53. Dhivya S, Padma VV, Santhini E (2015) Wound dressings - a review. BioMedicine 5(4): 22.
54. Li TT, Lou CW, Chen AP, Lee MC, Ho TF, et al (2016) Highly Absorbent Antibacterial Hemostatic Dressing for Healing Severe Hemorrhagic Wounds. Materials (Basel, Switzerland) 9(9): 793.

55. Petrulyte S (2008) Advanced textile materials and biopolymers in wound management. Dan Med Bull. 55(1): 72-77.

56. Eswaramoorthy N, McKenzie DR (2017) Plasma treatments of dressings for wound healing: a review. Biophysical reviews 9(6): 895-917.

57. Dabiri G, Damstetter E, Phillips T (2016) Choosing a Wound Dressing Based on Common Wound Characteristics. Advances in wound care 5(1): 32-41.

58. DeFrates KG, Moore R, Borgesi J, Lin G, Mulderig T, et al (2018) ProteinBased Fiber Materials in Medicine: A Review. Nanomaterials (Basel Switzerland) 8(7): 457.

59. Bhattarai DP, Aguilar LE, Park CH, Kim CS (2018) A Review on Properties of Natural and Synthetic Based Electrospun Fibrous Materials for Bone Tissue Engineering. Membranes 8(3): 62.

60. Qin Y (2008) The gel swelling properties of alginate fibers and their applications in wound management. Polymers for advanced technology 19(1): 6-14

61. Sood A, Granick MS, Tomaselli NL (2014) Wound Dressings and Comparative Effectiveness Data. Advances in wound care 3(8): 511-529.

62. Hickman DA, Pawlowski CL, Sekhon U, Marks J, Gupta AS (2018) Biomaterials and Advanced Technologies for Hemostatic Management of Bleeding. Advanced materials (Deerfield Beach Fla) 30(4)

63. Kravanja G, Primožič M, Knez Ž, Leitgeb M (2019) Chitosan-based (Nano) materials for Novel Biomedical Applications. Molecules (Basel Switzerland) 24(10): 1960.

64. Li J, Mooney DJ (2016) Designing hydrogels for controlled drug delivery. Nature reviews. Materials 1(12): 16071.

65. Onaciu A, Munteanu RA, Moldovan AI, Moldovan CS, Berindan Neagoe I (2019) Hydrogels Based Drug Delivery Synthesis, Characterization and Administration. Pharmaceutics 11(9): 432.

66. Mantha S, Pillai S, Khayambashi P, Upadhyay A, Zhang Y, et al (2019) Smart Hydrogels in Tissue Engineering and Regenerative Medicine. Materials (Basel Switzerland) 12(20): 3323.

67. Inoue A (2018) Characterization of PL-7 Family Alginate Lyases From Marine Organisms and Their Applications. Chapter 16. In Methods in Enzymology 605: 499-524.

68. Park KD, Wang X, Lee JY, Park KM, Zhang S, et al (2016) Research trends in biomimetic medical materials for tissue engineering: commentary. Biomaterials research 20: 8. 